\title{
Predictors of repeat voluntary counseling and testing for HIV among men who have sex with men from Metro Manila, Philippines: a reasoned action approach
}

\author{
Samuel Brando H. Piamonte
}

Department of Social Sciences, University of the Philippines Los Baños, Philippines

\begin{abstract}
Introduction: Routine and timely testing for human immunodeficiency virus (HIV) is a gateway towards early treatment. Identifying key factors that drive repeat testing can inform interventions to promote regular HIV testing. Using the Reasoned Action Approach (RAA, as per Fishbein \& Ajzen, 2010) as model, this study determined the predictors of repeat voluntary counseling and testing (VCT) for HIV after three to six months following receipt of a non-reactive test result among men who have sex with men (MSM) at risk of HIV infection.

Material and methods: A prospective study was implemented at a community-based HIV testing and treatment center in Metro Manila, Philippines. At baseline, participants answered a self-administered questionnaire to measure re-test intention and its determinants. Their repeat status was identified at follow-up. Two-hundred and fifty MSM who received a non-reactive HIV test result were recruited for the study.

Results: Behavioral attitude $(\beta=0.20, p<0.001)$, injunctive norms $(\beta=0.15, p<0.01)$, and perceived behavioral control $(\beta=0.46, p<0.001)$ significantly predicted repeat VCT intention and provided $37 \%$ of variance explained. Descriptive norms did not significantly predict re-test intention. Intention to re-test $(\beta=0.10, p=0.02)$ significantly predicted actual re-test status, and provided a $3 \%$ variance in actual repeat test status.

Conclusions: The RAA was partially confirmed. Interventions that influence perceived control of MSM over repeat VCT are recommended.
\end{abstract}

HIV AIDS Rev 2022; 21, 1: 77-82 DOI: https://doi.org/10.5114/hivar.2022.112574

Key words: HIV/AIDS, men who have sex with men, voluntary counseling and testing, re-testing, reasoned action approach.

\section{Introduction}

There has been an increasing incidence of human immunodeficiency virus (HIV) in the Philippines, where men who have sex with men (MSM) contribute significantly to

Address for correspondence: Samuel Brando H. Piamonte, University of the Philippines Los Baños, Los Baños, Laguna, 4031, Philippines, e-mail: shpiamonte@up.edu.ph the statistics [1]. Routine testing is important because early detection of the virus means the individual can be linked early to care; thus, the virus could be managed immediately,
Article history:

Received: 29.05.2020

Received in revised form: 06.04.2021

Accepted: 07.04.2021

Available online: 10.01.2022
International Journal

of HIV-Related Problems

HIV \& AIDS

R e v i e w 
and progression to acquired immunodeficiency syndrome (AIDS) could be stopped.

Identifying one's status as reactive to HIV or not can be attained through HIV testing. Centers for Disease Control and Prevention (2018) recommended at least annual HIV testing for sexually active gay person or bisexual men; although, it was mentioned that a number of sexually active gay people and bisexual men may benefit from a more frequent HIV testing, specifically every three to six months.

In order to shed light on repeat voluntary counseling and testing (VCT) intentions and actual VCT performance among MSM, this study used the Reasoned Action Approach (RAA) [2] as framework. It covers Theory of Planned Behavior (TPB) $[3,4]$ and its root, Theory of Reasoned Action (TRA) [5]. The model states that the immediate antecedent of performing a behavior is one's intention to do it; while intention is driven by attitude towards the behavior, injunctive and descriptive norms (the latter variable as addition to the TPB), and perceived behavioral control, in which TPB augmented to the TRA. Attitude towards the behavior refers to one's evaluation of performing the behavior of interest. Meanwhile, injunctive norms describe the perceived approval or disapproval of other persons in engaging in that behavior; while descriptive norms relate to the perception of what others typically do with regard to the behavior of interest. Finally, the perceived ease or difficulty in conducting the behavior reflects perceived behavioral control. The model can serve as framework in providing behavioral interventions by identifying the relative importance of attitudinal, normative, and control factors shaping intention and targeting the most significant among these.

Studies with extended-TPB models have been performed in the context of HIV testing. However, they provided varying results in terms of what drives testing intention [6-8]. Only one study has been identified to evaluate the power of descriptive norms [9]; thus, its' role in HIV testing is not yet well-understood. Moreover, none of the studies exclusively focused on recently tested individuals who received negative result as sample participants, and repeat testing as behavior of interest.

To provide intervention in promoting routine testing and to fill research gaps, the aim of this study was to determine significant predictors of repeat VCT for HIV within three to six months following a non-reactive screening result. Following the principles of RAA model, it was hypothesized that there was a positive relationship between intention to repeat VCT after three to six months and $\mathrm{H} 1$ : behavioral attitude, H2: injunctive norms, H3: descriptive norms, and $\mathrm{H} 4$ : perceived behavioral control. The intention to repeat the HIV test increases as the attitude becomes more positive, injunctive and descriptive norms becoming more supportive, and perceived control over this behavior becomes stronger. Also, it was hypothesized that this intention was positively related to actual re-test (H5), suggesting that repeat VCT was more possible with stronger re-test intentions.

\section{Material and methods}

\section{Research design}

A prospective study was implemented at a communitybased HIV testing and treatment center in Mandaluyong City, Philippines to address the objectives of the study. Baseline data gathering started in the second half of 2018 and follow-up was conducted during first quarter of 2019. Follow-up period ended six months after the last day of baseline data gathering.

\section{Research participants}

MSM clients who received a non-reactive HIV test result was informed by their respective counselors that a study on re-testing for HIV was being conducted at the center. If a person was interested in participating, counselors asked permission if they can disclose the person's non-reactive status to the principal investigator (PI) to avoid breach of privacy. If affirmative, a counselor called the PI to take over the counseling room. The PI explained further details of the study and performed screening process.

Inclusion criteria to participate were: 1) biologically assigned male who has sexual experience with other men; 2) aged 18 years or older; 3 ) studying, working, or residing in Metro Manila, 4) non-reactive to HIV antibodies based on HIV test done at the study site; 5) willing to provide contact information for a follow-up data gathering, and 6) has engaged in the following for the past twelve months: a) condomless sexual intercourse; b) multiple anal sex partners; c) multiple oral sex partners; d) sex under the influence of alcohol; e) sex under the influence of drugs, or f) trading money for sex, i.e. bought or sold sex. In total, two-hundred and fifty participants were successfully recruited into the study.

\section{Data and methods}

At baseline, a self-administered questionnaire measuring intention and its determinants was provided to all eligible participants. Based on existing guidelines on constructing items measuring the RAA variables [10-12], behavioral attitude was measured through a seven-point semantic differential scale, while other variables were measured through a five-point Likert scale. Instructions for follow-up were also provided to the participants during baseline.

Prior to the study, an earlier version of the questionnaire was pre-tested to an independent sample of 30 non-reactive MSM recruited from the same study site to assess for reliability of questionnaire items and to identify readability of the instrument. One item measuring PBC was removed since it did not contribute to an acceptable reliability level. Total scores for direct measurements ranged from 6 to 42 for attitude, and from 3 to 21 for both normative and control factors as well as intention. Table 1 presents the final scale items. 
Table 1. Measures of Reasoned Action Approach (RAA) variables with reliability scores

\begin{tabular}{|c|c|c|c|}
\hline Variable & Statements & Responses & Code \\
\hline $\begin{array}{l}\text { Intention } \\
(\alpha=0.93)\end{array}$ & $\begin{array}{c}\text { I expect to get tested again for HIV after } \\
\text { three to six months. } \\
\text { I want to get tested again... } \\
\text { I intend to get tested again... }\end{array}$ & $\begin{array}{l}\text { Strongly disagree to strongly agree } \\
\text { Strongly disagree to strongly agree } \\
\text { Strongly disagree to strongly agree }\end{array}$ & 1 to 7 \\
\hline $\begin{array}{l}\text { Attitude towards } \\
\text { behavior - ATB } \\
(\alpha=0.82)\end{array}$ & $\begin{array}{l}\text { Undergoing a repeat voluntary HIV testing } \\
\text { and counseling within the next three } \\
\text { to six months is... }\end{array}$ & $\begin{array}{l}\text { Extremely not beneficial to extremely beneficial } \\
\text { Extremely unimportant to extremely important } \\
\text { Extremely unnecessary to extremely necessary } \\
\text { Extremely unsatisfying to extremely satisfying } \\
\text { Extremely unpleasant to extremely pleasant } \\
\text { Extremely unexciting to extremely exciting }\end{array}$ & 1 to 7 \\
\hline $\begin{array}{l}\text { Injunctive norms - IN } \\
(\alpha=0.88)\end{array}$ & $\begin{array}{c}\text { Most people who are important to me } \\
\text { think that I should have a repeat HIV test } \\
\text { within the next three to six months } \\
\text { It is expected of me that I... } \\
\text { People who are important to me } \\
\text { want me to... }\end{array}$ & $\begin{array}{l}\text { Strongly disagree to strongly agree } \\
\text { Strongly disagree to strongly agree } \\
\text { Strongly disagree to strongly agree }\end{array}$ & 1 to 7 \\
\hline $\begin{array}{l}\text { Descriptive norms - DN } \\
(\alpha=0.86)\end{array}$ & $\begin{array}{l}\text { How many of the important persons } \\
\text { you know would get tested again within } \\
\text { three to six months after getting } \\
\text { a non-reactive result? } \\
\text { How likely are the persons important to you? } \\
\text { Getting a repeat test after three to six } \\
\text { months from receiving an HIV-negative } \\
\text { result is a common practice among } \\
\text { important persons I know. }\end{array}$ & $\begin{array}{l}\qquad \text { None to all } \\
\text { Extremely unlikely to extremely likely } \\
\text { Strongly disagree to strongly agree }\end{array}$ & 1 to 7 \\
\hline $\begin{array}{l}\text { Perceived behavioral } \\
\text { control - PBC } \\
(\alpha=0.76)\end{array}$ & $\begin{array}{l}\text { I am confident that I could get a repeat } \\
\text { HIV test after three to six months } \\
\text { if I wanted to. } \\
\text { For me to get tested again after three to } \\
\text { six months would be... } \\
\text { The decision to undergo a repeat HIV test } \\
\text { after three to six months is beyond my } \\
\text { control. }\end{array}$ & $\begin{array}{l}\text { Strongly disagree to strongly agree } \\
\text { Extremely impossible to extremely possible } \\
\text { Strongly disagree to strongly agree }\end{array}$ & 1 to 7 \\
\hline
\end{tabular}

Intention and its predictors were measured at the same level of specificity. In this way, the measures involved the same target, action, context, and time elements; thus, principle of compatibility [13] was followed. This principle requires independent variables and intentions to be assessed with respect to behavior in question to maximize the predictive power of antecedents. In this study, all measures focused on repeating HIV test for the next three to six months following the receipt of test result. Fishbein et al. [2] reported that greater correspondence between measures of intention and behavior produces higher correlation between them.

Dependent variable, re-test status, was measured during the follow-up phase. It was coded as ' 1 ' when a participant had a re-test within three to six months ( \pm 1 week), otherwise it was noted as ' 0 '. Three means were implemented by the researcher during follow-up phase to minimize loss to follow-up. After baseline data gathering, a drop box was placed at the study site and at another branch of the center in Pasay City, since other participants could undergo a repeat test at the other center. It contained envelopes, which the participants had to fill in to record a repeat test done within six months. In the second method, the study sites' records of the participants who did not fill in the questionnaires from the drop box were verified after six months from the recruitment to identify whether they returned or not. Finally, individuals with no records from the drop box and study sites' respective patients' databases were personally contacted to inquire if they had a repeat test elsewhere.

\section{Data analysis}

Descriptive measures were performed first to characterize the participants in terms of their socio-demographic data. Principal components analysis (PCA) with varimax rotation was applied to establish construct validity of the measurements of independent variables.

Correlation analyses, tolerance, and variance inflation factors (VIF) were firstly examined before multiple regression analysis to test multi-collinearity. To evaluate $\mathrm{H} 1$ to $\mathrm{H} 4$, 
multiple linear regression was applied. On the other hand, a logistic regression model was built to verify $\mathrm{H} 5$.

Data were encoded in a spreadsheet and was transferred to a statistical package for analyses. Significance was all set at $\alpha=0.05$. SAS University Edition (SAS Institute Inc., 2018) software for Mac OS was used to analyze statistical data.

\section{Ethical considerations}

The study protocol obtained ethics clearance from the University of the Philippines Manila Research Ethics Board (Study code, 2018-021-01). Written consent forms were prepared for both screening and data gathering procedures to elicit voluntary participation of the participants.

\section{Results}

\section{Socio-demographic profile}

The average age of the participants at baseline was 26 years old $(\mathrm{SD}=4.39)$ which indicated that they are in their productive years and that they belong to the high HIV-incidence age cohort. Majority of the cohort participants were identified as males (93\%). In terms of sexual orientation, majority was exclusively or more attracted to the same sex (63\%). The participants were educated, with $90 \%$ reported to have attended college. Typical income ranged from 30,001 to 40,000 Pesos (31\%); and most of the participants were not in a relationship (82\%). Finally, the mean number of HIV tests in lifetime was $4(\mathrm{SD}=3.30)$.

\section{Predictors of intention}

$\mathrm{KMO}$ measure of sampling adequacy value was 0.83 and Bartlett's test of sphericity was statistically significant $(p<0.001)$, indicating that the data were suited for PCA.
The results revealed that the items measuring predictors' load in their respective constructs were as expected, making the measures empirically distinct. Table 2 presents the correlation matrix among independent variables as well as descriptive statistics for scale scores to examine multicollinearity.

The respondents had a strong positive attitude towards a repeat HIV test after three to six months following receipt of non-reactive test result $(\overline{\mathrm{x}}=36.72, \mathrm{SD}=5.98)$. In terms of perceived norms, the respondents reported strong support from their environment with regards to a repeat HIV test $(\overline{\mathrm{x}}=15.88, \mathrm{SD}=4.85)$, and descriptive norms indicated that significant others are likely to conduct an HIV test $(\bar{x}=14.46, \mathrm{SD}=4.58)$. Composite score for perceived behavioral control indicated that the participants had a very strong perceived control over a re-test $(\overline{\mathrm{x}}=18.98, \mathrm{SD}=2.61)$.

Correlation analyses suggested that multi-collinearity was not a problem, with 0.51 as highest coefficient. Moreover, tolerance and VIF values supported this (ATB tolerance $=0.65, \mathrm{VIF}=1.53$; IN tolerance $=0.72$, VIF $0=1.39$; $\mathrm{DN}$ tolerance $=0.79, \mathrm{VIF}=1.27 ; \mathrm{PBC}$ tolerance $=0.73$, VIF $=1.36$ ). Table 3 presents regression coefficients predicting intention.

Regression coefficients indicated statistical significance in behavioral attitude, injunctive norms, and perceived behavioral control. MSM with more positive behavioral attitude $(\beta=0.20, t(245)=4.89, p<0.001)$, more supportive environment $(\beta=0.15, t(245)=3.06, p<0.01)$, and stronger perceived behavioral control $(\beta=0.46, t(245)=5.19$, $p<0.001$ ), had stronger intentions to repeat the test after three to six months. Perceived behavioral control emerged as the strongest predictor. These corroborated $\mathrm{H} 1, \mathrm{H} 2$, and $\mathrm{H} 4$; however, contrary to $\mathrm{H} 3$, descriptive norms did not emerge as a significant predictor $(\beta=-0.05, t(245)=-1.00$, $p=0.32$ ). The model accounted for $37 \%$ of variance in intention, with $F(4.245)=36.12$ and $p<0.001$.

Table 2. Correlation coefficients among independent variables

\begin{tabular}{l|c|c|c|c|c|c}
\hline Variables & Mean & SD & ATB & IN & DN & PBC \\
\hline ATB & 36.72 & 5.98 & 1.00 & - & - & - \\
\hline IN & 15.88 & 4.85 & $0.41^{*}$ & 1.00 & - & - \\
\hline DN & 14.46 & 4.58 & $0.31^{*}$ & $0.44^{*}$ & 1.00 & - \\
\hline PBC & 18.98 & 2.61 & $0.51^{\star}$ & $0.28^{*}$ & $0.21^{*}$ & 1.00 \\
\hline
\end{tabular}

${ }^{*}$ Significant at $p$-value $<0.001$

Table 3. Multiple regression coefficients predicting re-test intention

\begin{tabular}{l|c|c|c|c|c}
\hline Variables & Unstandardized $\beta$ & Standardized $\beta$ & $t$ & df & $p$-value \\
\hline ATB & 0.20 & 0.31 & 4.89 & 245 & $<0.001$ \\
\hline SN & 0.15 & 0.18 & 3.06 & 245 & $<0.01$ \\
\hline DN & -0.05 & -0.06 & -1.00 & 245 & 0.32 \\
\hline PBC & 0.46 & 0.31 & 5.19 & 245 & $<0.001$ \\
\hline
\end{tabular}




\section{Intention-behavior relationship}

Data on repeat test status was obtained from 209 individuals, indicating $16 \%$ of lost to follow-up. Among them, less than half $(46 \%)$ reported to undergo a repeat HIV test between three and six months after baseline. In terms of predicting actual performance of a re-test following a receipt of a non-reactive test result, re-test intention significantly predicted actual repeat test status $(\beta=0.10$, $p=0.02$ ), corroborating $\mathrm{H} 5$, which explained $3 \%$ of the variance in repeat test status. This supports the hypothesis that those with stronger intention to re-test were more likely to do so.

\section{Discussion}

The present study revealed that evaluation of a repeat test exerts influence on intention to conduct a follow-up VCT. MSM are more likely to form stronger repeat test intentions if they have favorable opinions about the consequences of a repeat test. Similarly, the perceived social support from significant others impacts re-test intentions, suggesting that MSM would have stronger intention to conduct a re-test in a supportive environment. Finally, the perceived easiness or difficulty of another uptake of an HIV test for the next three to six months also significantly influences intention. MSM are more likely to form stronger repeat test intentions if they perceive that they are surrounded by more facilitating factors, rather than barriers. Descriptive norms did not emerge as a significant predictor, which means that the perception on whether others would also get tested did not affect repeat testing intention.

Studies utilizing the TPB as framework to investigate HIV testing intentions consistently highlighted behavioral attitude as a significant predictor. In Mirkuzie et al. [9], attitude towards behavior, injunctive, descriptive norms, and perceived barriers, all predicted HIV testing intention among pregnant women attending public health facilities; however, in private facilities, only behavioral attitude and injunctive norms were reported as significant. In Abamecha et al. [6], attitude towards behavior and injunctive norms emerged as significant predictors. Meanwhile, other studies [7, 14, 15] indicated significance of attitude and control factors, but not injunctive norms. In the current study, only descriptive norms did not emerge as a significant determinant of intention.

The reported variance explained in intention to re-test of HIV test was higher than that in existing studies using TPB in the context of HIV testing. It was greater than the variances reported by Meadowbrooke et al. [8] in their study of young MSM with and without prior HIV test, Abamecha et al. [6] in their study involving health professionals with and without HTC experience, and by Ayodele who studied students who have never been tested for HIV [15]. Although previous research and the current study concerns HIV testing, a difference in the current study concerns re-testing for HIV among MSM with non-reactive test results.
A number of studies using the RAA in the context of HIV testing were only limited to prediction of intention $[6,8,16]$. However, the current study employed a prospective design in order to examine whether intention translates into actual behavioral performance. In this research, the relationship between intention and behavior was examined in the context of repeat HIV testing following a receipt of non-reactive test result. It was observed that MSM who had strong repeat test intentions were more likely to undergo repeat VCT; thus, providing evidence for the intention-behavior relationship.

The RAA as a behavior change model suggests that changing intention through attitudinal, normative, and control factors can also trigger a change in behavior. Therefore, this theory can be used not just to understand a particular health-related behavior but also its change [17]. It cannot suggest what interventions can be effective but it can provide guidelines on how to develop behavioral interventions, including persuasive communication, face-to-face discussions, and observational modeling [18]. This study provides evidence on how to increase re-testing among MSM with increased risk of HIV infection. As perceived behavioral control was the identified strongest predictor, the study recommends communication campaigns informing MSM of ways to facilitate repeat tests, including information on accessibility and availability of HTC sites. It must be noted that HIV testing is one of the mechanisms to prevent transmission of HIV. Along with promotion of routine and timely testing, program administrators and policy-makers involved in HIV/AIDS should also consider a combination of preventive methods against HIV transmission, such as providing pre-exposure prophylaxis for suitable candidates.

Despite its strengths, the current study have various limitations. The target population of the study included only MSM who were working, residing, or studying in Metro Manila, and were at risk of acquiring HIV. This was the chosen cohort since the incidence of HIV in this population is high. Therefore, the results of the study may differ if study was reproduced in another population, such as sex workers, injection drug users, or MSM with no engagement in risky sexual behaviors. Moreover, specific messages to convey for interventions targeting routing VCT for HIV could not be provided in the present paper. In order to do this, significant beliefs of MSM toward repeat VCT must be extracted and tested to identify which of these significantly shape behavioral attitude, norms, and perceived behavioral control. Finally, the research was only a single-center study and similar projects in the future are recommended to employ multi-center sites to validate its external validity.

\section{Conclusions}

The study partially confirms the Reasoned Action Approach. It provided substantial variance in repeat test intentions but less in actual repeat test status. Programs that strengthen MSM's perceived control over re-testing for HIV should be 
implemented to promote routine testing and consequently, HIV/AIDS prevention.

\section{Acknowledgement}

The author would like to thank UPLB Gender Center and LoveYourself, Inc. for the support.

\section{Conflict of interest}

The author declares no conflict of interest.

\section{References}

1. Department of Health. HIV/AIDS and ART Registry of the Philippines. Department of Health Epidemiology Bureau 2019. Retrieved from: https://www.doh.gov.ph/sites/default/files/statistics/ EB_HARP_Report_January2019.pdf.

2. Fishbein M, Ajzen I. Predicting and Changing Behavior: the Reasoned Action Approach. New York: Psychology Press; 2010.

3. Kuhl J, Beckmann J (eds.). From Intentions to Actions: a Theory of Planned Behavior. Berlin, Heidelberg: Springer; 1985, pp. 11-39.

4. Ajzen I. The theory of planned behavior. Organizational Behavior And Human Decision Processes 1991; 50: 179-211.

5. Fishbein M, Ajzen I. Belief, Attitude, Intention, and Behavior: an Introduction to Theory and Research. Reading, MA: AddisonWesley; 1975.

6. Abamecha F, Godesso A, Girma E. Predicting intention to use voluntary HIV counseling and testing services among health professionals in Jimma, Ethopia, using the theory of planned behavior. J Multidiscip Healthc 2013; 6: 399-407.

7. Kakoko DC, Åstrøm AN, Lugoe WL, Lie GT. Predicting intended use of voluntary HIV counselling and testing services among Tanzanian teachers using the theory of planned behaviour. Soc Sci Med 2004; 63: 991-999.

8. Meadowbrooke CC, Veinot TC, Loveluck J, Hickok A, Bauermeister J. Information behavior and HIV testing intentions among young men at risk for HIV/AIDS. J Assoc Inf Sci Technol 2014; 65: 609-620.

9. Mirkuzie AH, Sisay MM, Moland KM, Astrøm AN. Applying the theory of planned behavior to explain HIV testing in antenatal settings in Addis Ababa - a cohort study. BMC Health Serv Res 2011; 11: 196.

10. Ajzen I, Fishbein M. Scaling and testing multiplicative combinations in the expectancy-value model of attitudes. J Appl Soc Psychol 2008; 38: 2222-2247.

11. Francis J, Eccles MP, Johnston M, et al. Constructing questionnaires based on the theory of planned behaviour: a manual for health services researchers. Newcastle upon Tyne, UK: Centre for Health Services Research, University of Newcastle upon Tyne; 2004.

12. Glanz K, Rimer BK, Viswanath K (eds.). Theory of Reasoned Action, Theory of Planned Behavior, and the Integrated Behavioral Model. San Francisco, CA: Jossey-Bass; 2008, pp. 67-96.

13. Ajzen I. Attitudes, personality, and behavior. Homewood, IL: Dorsey Press; 1988.

14. Mtenga SM, Exavery A, Kakoko D, Geubbels E. Social cognitive determinants of HIV voluntary counseling and testing uptake among married individuals in Dar es Salaam, Tanzania: theory of planned behavior (TPB). BMC Public Health 2015; 15: 213.

15. Ayodele $\mathrm{O}$. The theory of planned behavior as a predictor of HIV testing intention. Am J Health Behav 2013; 41: 147-151.

16. Westmaas AH, Kok G, Vriens P, Götz H, Richardus JH, Voeten H. Determinants of intention to get tested for STI/HIV among the Surinamese and Antilleans in the Netherlands: results of an online survey. BMC Public Health 2012; 12: 961.
17. Fishbein M. A reasoned action approach to health promotion. Med Decis Making 2008; 28: 834-844.

18. Ajzen I. Attitudes, Personality and Behavior. $2^{\text {nd }}$ ed. Berkshire: Open University Press/McGraw-Hill Education; 2005. 